\title{
Arqueologia dos Supervilões: como o "mal" é representado nas histórias em quadrinhos
}

\author{
Marcelo Bolshaw Gomes ${ }^{1}$ \\ Universidade Federal do Rio Grande do Norte
}

\begin{abstract}
Resumo
Problematiza o conteúdo simbólico e a representação do mal através dos vilões dos dois principais universos narrativos das histórias em quadrinhos: DC Comics e Marvel. Por meio da noção de Anti-sujeito de Greimas, analisa-se cada personagem e como ele se encaixa em seu universo narrativo. O objetivo é, a partir de uma arqueologia de antagonistas, esboçar uma anatomia do mal narrativo em suas variadas versões.
\end{abstract}

Palavras-chave: Comunicação midiática. Histórias em quadrinhos. Representação do mal.

\begin{abstract}
Problematizes the symbolic content and the representation of evil through the villains of the two main narrative universes of comics: DC Comics and Marvel. Through the notion of Greimas's Anti-subject, each character is analyzed and how it fits into his narrative universe. The goal is, from an archeology of antagonists, to sketch an anatomy of narrative evil in its various versions.
\end{abstract}

Keywords: Media communication. Comic books. Representation of evil.

\section{Introdução}

As narrativas de super-heróis e de ficção científica são uma nova forma de mitologia, voltada para o futuro (e não apenas para o passado - como a mitologia clássica). Estudar essas narrativas midiáticas é investigar a organização dos símbolos no imaginário coletivo atual. Há universos narrativos mais centrados na dicotomia entre o bem e o mal, como as histórias dos contos de fada, muitas vezes afirmando crenças do simbolismo dominante - tanto em relação à política como à religião. Por outro lado, essas narrativas são socialmente críticas, laicas e até antirreligiosas: os deuses são alienigenas e a magia foi combinada e/ou substituida pela tecnologia.

${ }^{1}$ Professor Adjunto do Departamento de Comunicação Social da Universidade Federal do Rio Grande do Norte. Email: marcelobolshaw@ufrnet.br. ORCid: https://orcid.org/0000-0002-8227-3672. 
Assim como as tradições religiosas do passado, os universos narrativos de ficção atuais também têm suas cosmologias, povoadas por seres semieternos, cuja existência precedeu e vai suceder a dos humanos e de seus super-heróis.

O conceito de 'mal' (e de sua representação) sempre foi uma das discussões filosóficas e teológicas mais intrigantes. Religiosos como Agostinho de Hipona (1973) e Paul Ricouer (2013), entre outros, problematizam o tema como uma 'dialética quebrada' ou um paradoxo: “(...) como se pode afirmar conjuntamente, sem contradição, as três proposições seguintes: Deus é todo poderoso; Deus é absolutamente bom; contudo, o mal existe" (RICOEUR, 1988, p. 21).

Por outro lado, céticos e materialistas como Freud e Nietzsche tentam, em vão, entender a auto destrutividade humana diante da natureza e de si mesmo como sendo uma pulsão de morte ou uma vontade mórbida de poder.

O criador da cibernética, Norbert Wiener (1954) considera que o 'mal' é equivalente ao ruído comunicacional. Para ele, estamos mergulhados no caos e o universo tende à entropia, isto é, a desorganização estrutural. Wiener discriminava dois tipos de ruído: o Diabo Agostiniano e o Diabo Maniqueu. Para compreender esta analogia, é preciso lembrar que Santo Agostinho, antes de ser Bispo de Hipona, participou da seita herética dos maniqueus. Os maniqueus acreditavam louvar a totalidade de Deus, adorando tanto o Cristo quanto o Diabo. Para esta seita (o "maniqueísmo"), o bem e o mal são opostos e complementares que formam juntos a totalidade divina. Agostinho, no entanto, rompeu com essa concepção quando elaborou a doutrina do pecado original, segundo a qual Deus é infinitamente bom e misericordioso, e o mal só existe por causa do próprio homem, que foi expulso do Éden e agora luta para retornar a sua condição original.

Wiener diz que a ciência (ou a relação entre o homem e a natureza) corresponde à luta contra a irracionalidade do diabo agostiniano porque a natureza não inventa ardis para nos enganar e o ruído resulta de nossa própria ignorância, ao passo que a política (ou a relação dos homens entre si) representa um embate contra a irracionalidade do diabo maniqueu, em que o ruído é utilizado para enganar o adversário (e para se enganar). Nessa perspectiva, há um 'mal objetivo', a força entrópica desagregadora do universo; e um 'mal intersubjetivo', a bestialidade humana, que corresponde ao ruído comunicacional.

Nas narrativas, o mal intersubjetivo é representado por um personagem e o mal objetivo por um tipo de impedimento (amoroso, moral, tecnológico). 


\section{1 - Método: o mal narrativo}

Para Greimas $(1976,2002)$, nas narrativas, alguém (O SUJEITO) deseja alcançar algo (O OBJETO DE VALOR) e é atrapalhado por algo/alguém (O ANTISUJEITO). Este modelo simples permite entender o gênero (que tipo de objeto de valor) e a ideologia (a identidade do antisujeito) da narrativa. No caso da gravidez, o diagnóstico da substância de expressão: a mãe é o actante sujeito; a futura criança, o objeto de valor; e o antisujeito, define o tipo de narrativa: gravidez de risco, gravidez indesejada, gravidez constrangedora. E, finalmente, a substância de conteúdo se refere aos elementos simbólicos e psicológicos da narrativa, aos 'universais do imaginário', que combinados de diferentes modos formam a "mensagem" da narrativa.

Greimas sugere a organização desses elementos em pares, representando os conflitos, relações complementares e contrapontos da narrativa, em modelo chamado de Quadrado Semiótico Narrativo. Este modelo consiste em definir quatro actantes e organizá-los em seis pares de opostos: duas relações de contradição; duas relações de contrariedade; e duas relações de complementaridade - entre os quatro elementos simbólicos principais da narrativa. Essas estruturas profundas seriam lógicas e acrônicas, formadas por relações de contradição, oposição e contraponto (o quadrado semiótico).

O artigo "O herói de duas faces" (GOMES, 2016) estabelece um modelo, apresentado no quadro 1 , abaixo:

Quadro 1: Quadrado Semiótico Narrativo do super-heroismo

\begin{tabular}{|c|c|}
\hline Herói protagonista (Mito) & Antagonista (Ideologia combatida) \\
\hline Leitor (Identidade cotidiana) & Universo Narrativo (Midia) \\
\hline \multicolumn{2}{|c|}{ FONTE: Revista $9^{\mathrm{a}}$ Arte, v. 5, n. 2, 2016. }
\end{tabular}

Os super-heróis são a representação dos mitos e arquétipos, mediados ideologicamente dentro da linguagem fragmentada e descontínua da mídia, em seus múltiplos suportes atuais. Há, portanto, quatro aspectos da mediação da identidade narrativa dos super-heróis: a psicanálise dos desejos inibidos do leitor (a representação da relação eu/outro através da dupla identidade); o conteúdo mítico 
e/ou arquetípico do protagonismo; a linguagem fragmentada e repetitiva da mídia como narradora; e a dimensão ideológica do antagonismo. O mito precisa ser repaginado ideologicamente de acordo com o contexto social e os pactos de leitura; principalmente através de novos inimigos, mas também através de mudanças estéticas, narrativas e editoriais. Os inimigos geralmente representam antagonistas sociais, como o nazismo da Era de Ouro dos quadrinhos de super-heróis; os países socialistas, nas Eras de Prata e Bronze; e o terrorismo e a corrupção, em suas diferentes versões, na atualidade (ANDREOTTI; MARANGONI; ZANOLINI, 2017).

$\mathrm{O}$ antisujeito narrativo é a representação de tudo que impede o sujeito de conquistar seu objeto de valor, não apenas quando estão encarnados em personagens: monstros, alienígenas, máquinas) mas também como formas de adversidade (doenças, catástrofes ambientais, dramas emocionais, etc). A arqueologia completa dos vilões de um universo narrativo, formado por milhares de histórias, desenha uma anatomia dos ruídos imaginativos, não apenas das coisas que tememos, mas de como e por que tememos, de qual papel o medo desempenha em nossas histórias e em nossas vidas.

\section{2 - Universo narrativo}

Universo narrativo é um mundo ficcional em que acontece um determinado tipo de histórias. Ele é diferente do mero cenário, são os detalhes e o nível de consistência interna, o que permite a intertextualidade entre as histórias - que podem ser contadas por vários autores e por diferentes meios: romances, quadrinhos, filmes, programas de televisão, videogames e outros trabalhos criativos.

Há universos narrativos que são praticamente indistinguíveis do universo real, exceto pela presença dos personagens e acontecimentos inventados da narrativa. Outros são abertamente fantásticos, mas sempre guardam elementos simbólicos semelhantes à realidade, para estabelecer analogias e inferências indiretas do leitor. A maioria dos universos narrativos são híbridos dos dois aspectos: a representação da realidade e a imaginação.

Homero (2003), por exemplo, trata da relação entre a guerra de Troia (que foi real) e da vida dos deuses do Olimpo. Frank Baum (2014) descreve a terra de Oz como uma realidade alternativa à vida rural do Kansas. Um exemplo famoso de um universo narrativo literário é a saga O Senhor dos Anéis de J. R. R. Tolkien (2002), 
que cria linguas próprias para as diferentes 'raças' que compõem a narrativa. Outro, mais recente, é o universo narrativo audiovisual do filme Avatar (2009), de James Cameron, que inventou todo um ecossistema biológico e a linguagem Na'vi para uma espécie alienigena.

Hoje, praticamente todas as séries de TV desenvolvem seu próprio 'universo'. E os escritores para cada série devem seguir um 'cânone': linhas do tempo, locais, características dos personagens, etc. Os universos atuais são compartilhados não apenas por autores, mas também pelo público, que produz narrativas em seu contexto.

O livro Universos sci-fi audiovisuais: estudos narrativos transmidia II (GOMES, 2016a) discute cinco universos narrativos diferentes de ficção cientifica Star Trek (1966-2005), Stargate (1994-2011), Babylon 5 (1994-1999), Battlestar Galactica (1978-2010) e Alien vs Predador (1979-2015). Tratava-se de mostrar como esses universos - com histórias na televisão, no cinema, nos livros e em quadrinhos - serviram de laboratório para a transmediação das narrativas. O termo 'narrativa transmídia' foi elaborado por Jenkins (2008), levando em conta três elementos: a) a participação da audiência na elaboração da história; b) a sugestão de que o universo ficcional é uma realidade narrativa; c) a presença dos principais personagens da narrativa em diferentes suportes. Segundo Jenkins, desde meados dos anos 90 já é possivel identificar produções de narrativas transmidiáticas na indústria de entretenimento, destacando os universos de Matrix e do seriado Lost. Este último utilizou vários recursos: minivideos para celular com histórias rápidas que não passam na TV, perfis dos personagens na internet, podcasts (arquivos de áudio) semanais discutindo os episódios e entrevistando os atores, diretores, produtores e roteiristas da série, a lostpédia (uma enciclopédia wiki criada por fãs), e um site falso da empresa aérea Oceanic Airlines, supostamente responsável pelo desaparecimento dos personagens após um acidente.

Talvez por ocuparem uma posição intermediária entre os universos narrativos literários e audiovisuais, talvez por sua periodicidade regular durante longos períodos de tempo, os universos narrativos das histórias em quadrinhos se desenvolveram de modo peculiar e pioneiro, gerando regras, elementos e procedimentos, que passaram a ser adotados pelos universos transmídia atuais: o crossover, o reboot, o multiverso. 
- Crossover é um evento fictício em que dois ou mais personagens, cenários ou acontecimentos de universos narrativos diferentes, sem qualquer relação anterior passam a interagir em uma mesma história. É comum que crossovers sejam realizados entre produtos de uma mesma empresa, mas também acontece de fãs produzirem narrativas misturando, sem autorização, os personagens de diferentes franquias: Sherlock Holmes e Drácula, Naruto e Dragon Ball, Liga da Justiça (da DC Comics) e os Vingadores (da Marvel).

- Multiverso é um termo usado para descrever, na física quântica, o conjunto hipotético de universos possíveis, incluindo o universo em que vivemos. $\mathrm{Na}$ literatura, o multiverso é o 'mundo dos sonhos', o 'reino mágico', o 'mundo espiritual' - dimensões alternativas à realidade dentro do universo narrativo. O multiverso narrativo é um convite a aceitarmos que nossa realidade também tem dimensões alternativas reais e que a narrativa existe com relação à nossa vida. Hoje em dia, para representar o cotidiano, todos universos narrativos são multiversais, combinando elementos 'reais' e simbólicos; e embutindo dimensões alternativas na representação do real.

- Reboot (Continuidade retroativa) é a reinicialização do universo narrativo. Um reboot difere do remake e da prequela, que são mudanças consistentes com o cânone estabelecido. O remake se propõe a refazer um filme ou série de TV, mantendo personagens, eventos, ou mesmo toda a história. Uma prequela conta uma história inicial que não tenha sido encenada antes, sendo capaz de "corrigir" através do retcon, alguns aspectos até mesmo criar uma inconsistência com o histórico existente. Geralmente são realizadas pela mesma equipe criativa envolvida na continuidade. O reboot é uma reestruturação geral dos arcos narrativos, que 'salva' alguns elementos do universo (personagens, locais e conceitos), mas ignora a continuidade das histórias anteriores, substituindo-a por um novo cânone.

\section{3 - Universos narrativos de quadrinhos}

As histórias em quadrinhos - produtos síntese de uma indústria criativa que mistura autoria com estratégias de distribuição em escala industrial - tornou o universo dos super-heróis um dos mais ricos e complexos campos de testes comunicacionais entre os diversos mercados de "contação de histórias", tensionando de formas inovadoras e criativas o uso de ferramentas narrativas em sua intersecção entre objetivos estéticos com objetivos de mercado. Os quadrinhos têm explorado a estrutura narrativa como nenhum outro meio. Estas técnicas - que incluem coisas como arcos, crossovers, team-ups, reboots e múltiplos títulos "ligados" em séries maxi-story - vendem mais quadrinhos, mas no processo, eles podem estar desvendando caminhos para novas formas de contar histórias complexas. Os super-heróis dos comics interagem em seriados de tv, filmes de Hollywood, séries animadas para vídeo, games, etc. Dentro desse contexto, é natural o desenvolvimento de ferramentas narrativas que gerenciem e vinculem coerentemente esse emaranhado de histórias e manifestações midiáticas, orquestrando mundos ficcionais e personagens a partir de uma série de dispositivos que se destinam a públicos, suportes e linguagem diferentes. Acrescente-se em complexidade 0 fato de que essa orquestração de conteúdos frequentemente deve ser planejada 
considerando-se as ações pontuais de marketing de cada editora/estúdio (MOSSMANN, BRANCO, 2012, p. 05).

O conflito entre muitos anos de serialização e a necessidade de coerência intertextual do mundo narrado, levou, nos quadrinhos, reboot de todo universo narrativo da DC. A história "Flash of Two Worlds", em 1962, marca a primeira repaginação completa do universo $\mathrm{DC}$. A partir dela, todos os heróis da editora na Era de Ouro e suas histórias passam a pertencer a um universo paralelo: a Terra 2. Os heróis foram duplicados em versões mais jovens, tiveram seus trajes redesenhados, diferenças entre histórias antigas foram resolvidas, a linha do tempo foi reestruturada ${ }^{2}$.

Em 1985, a DC Comics decidiu unificar todas as suas publicações sob um único universo narrativo coeso e compartilhado, através da história 'Crise nas Infinitas Terras', destruindo todas as 'terras paralelas' e encerrando a continuidade e estabelecendo uma nova, repaginando novamente os personagens da DC Comics e acabando com o conceito de 'multiverso'. Esse novo período foi batizado de "Os novos $52^{\prime \prime}$ e foi recentemente (em 2011) encerrado por um terceiro reboot, o Renascimento, em que os personagens retornam ao universo Era de Ouro acrescido de outras continuidades intertextuais.

Já o universo Marvel é totalmente multiversal e compartilhado, incluindo além de outros locais e dimensões alternativas (os heróis habitam a terra 616 ou terra primal), outras continuidades intertextuais como o Esquadrão Supremo (um grupo personagens de uma Terra paralela e que foram inspirados na Liga da Justiça da editora rival da Marvel, a DC Comics) e as revistas "E se" (histórias que mostram como seriam eventos e personagens caso eles acontecessem de modo diverso ao que foi narrado nas revistas). Seus reboots são específicos. O Homem-Aranha, por exemplo, passou por vários reboots sem que afetasse outros heróis. Thor, Hulk, Namor, os Defensores e os X-men já passaram por reboots específicos para serem adaptados para TV ou para cinema.

Em 2000, a Marvel fez um reboot total com a série Ultimate Marvel em todo seu multiverso; e, mais recentemente, em 2018, com a série de Guerra Infinita nos quadrinhos e no cinema. No entanto, diferente dos reboots da concorrência, o universo original continua sendo publicado como se as duas séries fossem 
universos paralelos. Também no arco All New All Different Marvel, as histórias em quadrinhos voltam para o $\mathrm{n}^{\circ} 1$, mas o universo segue sua continuidade.

\section{4 - Os vilőes da DC}

Os vilões do universo DC são bastante ligados a heróis especificos. Lex Luthor, Brainiac 5 e o duende Mxyzptlk são antagonistas especificos do Superman; Coringa, Pinguim e Mulher-gato são adversários particulares do Batman; e a Mulher Maravilha tanto tem inimigos mitológicos como Ares, o deus grego da guerra, quanto "históricos" como o nazismo. Com a Liga da Justiça surgem também os grupos de super-vilões, reunindo inimigos que antes eram especificos (o Esquadrão Suicida, a Liga da Injustiça, a Legião do Mal). Há vários vilões-gêmeos dos heróis (como Bizarro e o Superman). E muitos heróis que se tornam vilões (Jason Todd, Hal Jordan).

Assim, uma arqueologia dos vilões da DC seria semelhante a uma arqueologia de seus super-heróis. Subdivididos em cósmicos/míticos (como o Apocalipse) e cotidianos (como o Duas-caras), haveria os vilões-monstro; os vilõesmáquina; os vilões-deuses; de acordo com o totem adotado para simbolizar o self. Também seria importante saber o que cada um tem a oferecer (para ser combatido). Isso pode ser avaliado melhor pelo Quadro 2, a seguir:

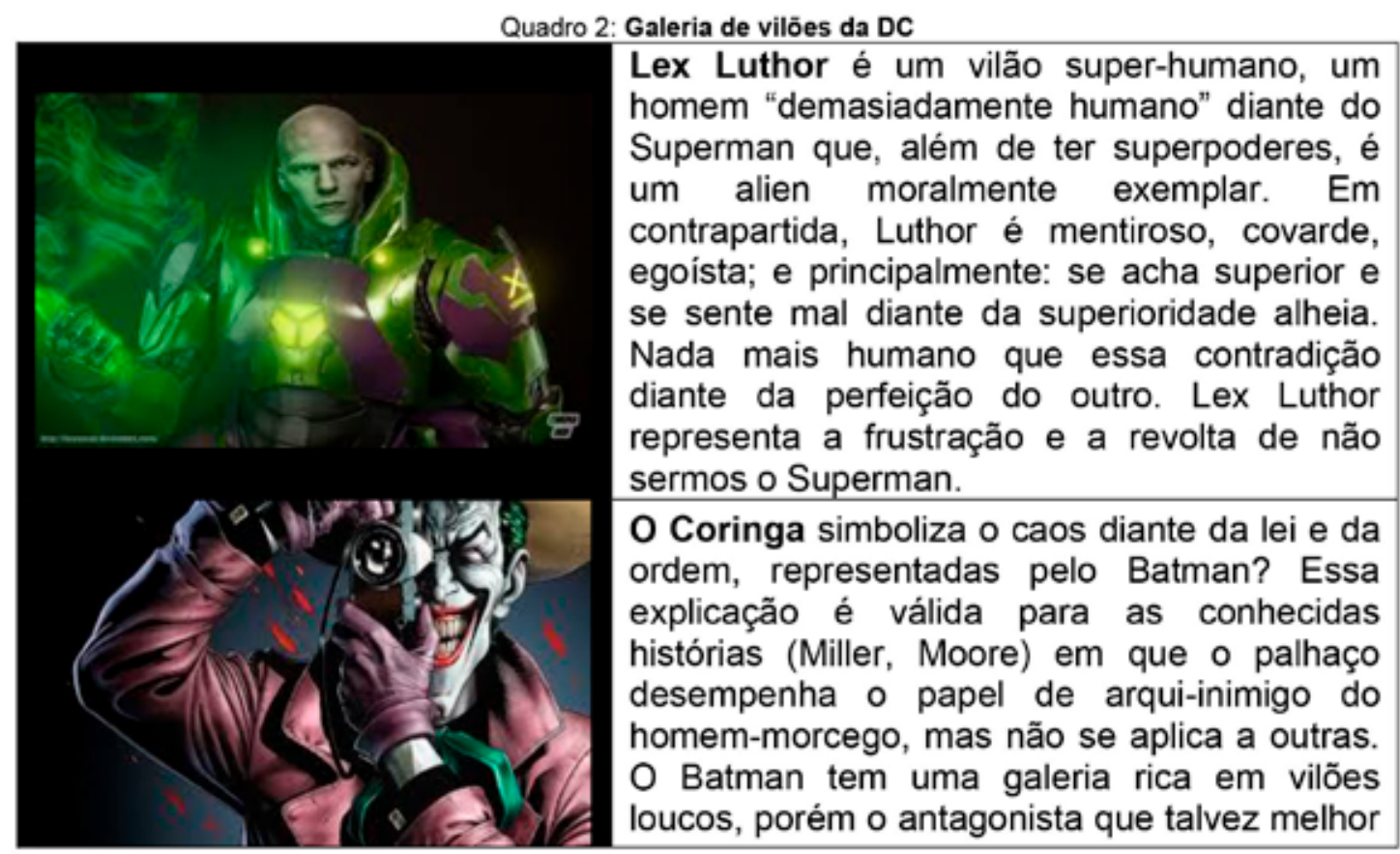




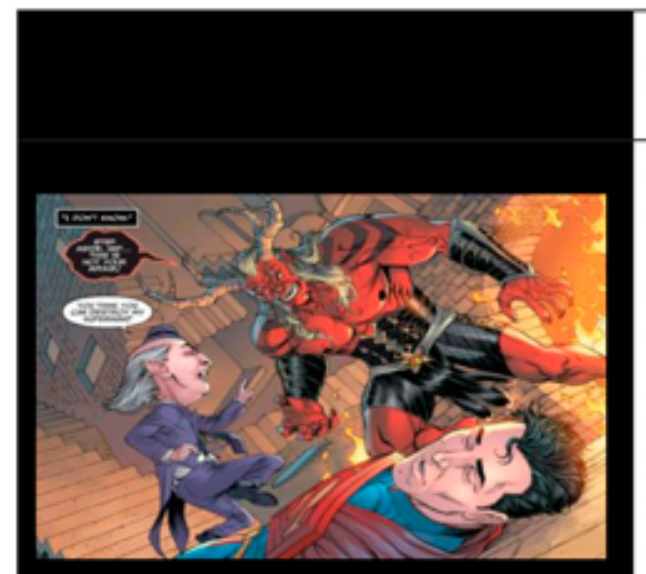

defina o protagonista seja Ra's Al Ghul, líder imortal da seita dos assassinos, que deseja purificar a humanidade.

Mr. Mxyzptlk, sugirdo em 1944, é um duende de poderes ilimitados da quinta dimensão e o único jeito de derrotá-lo é fazer com que diga seu nome ao contrário. Portanto, de nada valem os superpoderes, a única forma de vencê-lo é através da astúcia. Ao contrário dos vilões do cotidiano, os vilões mágicos não desejam dinheiro ou poder material. A intenção de Mxyzptlk é se vingar e se divertir e fazer com que o homem de aço faça papel de bobo, desmoralizando-o.

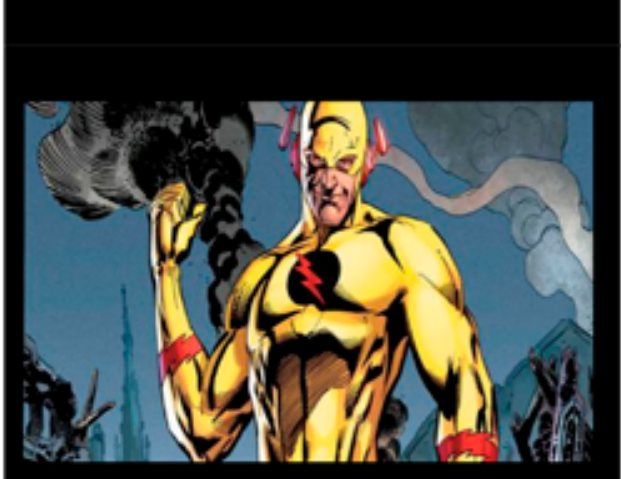

Flash Reverso, surgido em setembro de 1963, é um exemplo de vilão duplicado do super-herói. Ele era o professor universitário Dr. Edward Clariss, que acreditou ter duplicado a fórmula que deu ao primeiro Flash (Jay Garrick) seus poderes. A comunidade científica $\circ$ rejeitou e ele se tornou criminoso, usando uma versão sombria do uniforme de Era de Ouro. Flash reverso é um símbolo da sombra (do lado negativo) que todos temos e não conseguimos vencer.

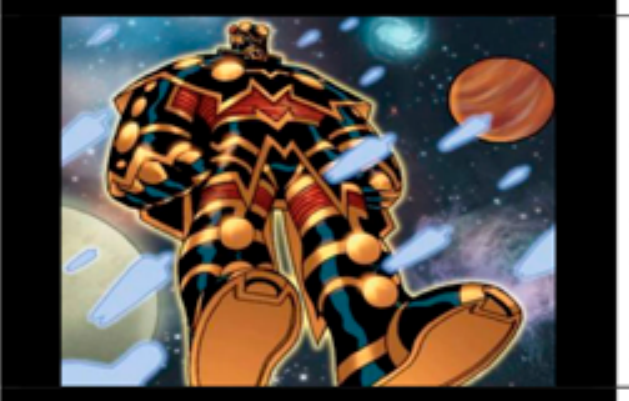

Imperiex, o "Devorador de Galáxias", criado por Jeph Loeb e lan Churchil, não é exatamente um vilão, mas um ser equivocado. Desde o começo dos tempos, ele destrói o universo e o recria de seus restos, tentando assim construir um universo novo e perfeito. Em sua última tentativa, é enviado pelos heróis para bilhões de anos no passado.

O Antimonitor desempenha o papel de antagonista na minissérie Crise nas Infinitas Terras (originalmente publicada em 1986) contraparte de Anti-Matéria do Monitor, encarnação do Multiverso. Ele foi formado na gênesis DC, quando o malthusiano Krona, provoca a separação do universo em várias dimensões (as terras 1, 2, 3 ...) e o universo Qward de Anti-matéria. O Antimonitor é um ser destruidor por natureza, ele apaga a realidade indiscriminadamente, sem nenhuma consciência moral. Na saga Crise nas Infinitas Terras, ele acorda de um longo sono com fome e quer apagar toda a criação, se alimentando do Multiverso. Os Vingadores só conseguem derrotá-lo graças ao super-vilão Darkseid. 


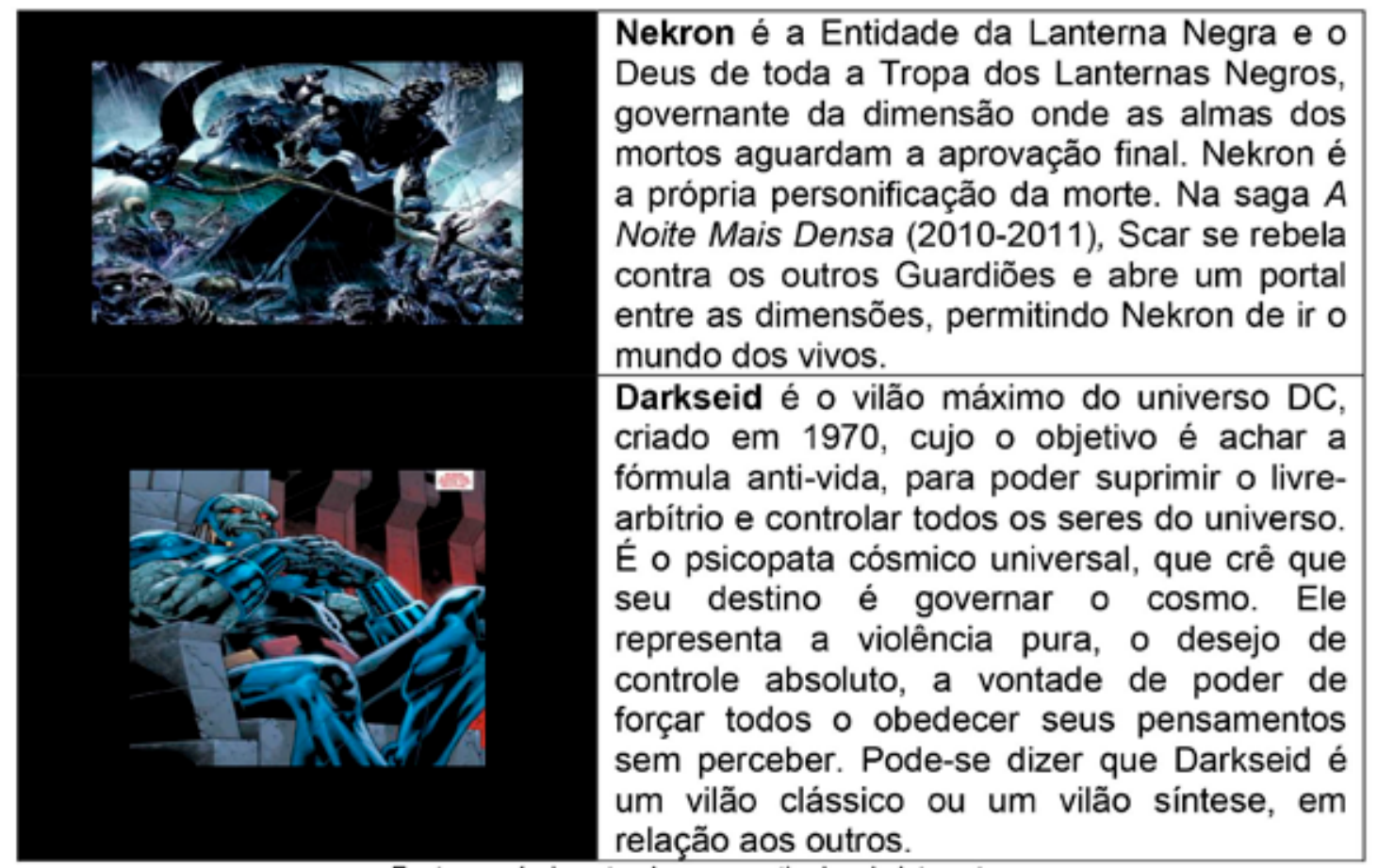

Fonte: o próprio autor. Imagens retiradas da Internet.

\section{5 - Os vilões da Marvel}

O universo DC se formou pela somatória de narrativas individuais e foi buscando uma coesão intertextual interna; o universo Marvel, no sentido contrário, "cresce de dentro para fora", agregando cada vez mais novas possibilidades e variações da armadura narrativa central. Outra diferença marcante é que enquanto o universo DC é mais voltado para relação entre passado e presente, reescrevendo várias vezes sua Genesis; o universo Marvel é voltado para relação entre o presente e o futuro, o apocalipse ${ }^{3}$.

Nos universos narrativos dos quadrinhos o Ragnarök (ou a batalha do final dos tempos) se desenvolve em diversas dimensões, em diferentes épocas e em vários locais do espaço-tempo. No multiverso Marvel, a narrativa geral das histórias caminha para uma apoteose trágica, centralizando uma única solução de muitas histórias e o começo de outras, um retorno a suas próprias origens em uma escala superior.

\footnotetext{
${ }^{3}$ Apocalipse é um elemento presente no universo narrativo de diversas culturas tradicionais. Ele não é um evento histórico, ele significa a "revelação" da eternidade. Para antiga Índia e para Pérsia, tratava-se de uma grande guerra entre os Devas e os Asuras, guerra essa que se estende até os nossos dias, uma guerra entre forças demoniacas e falanges angelicais ou ainda o 'crepúsculo dos deuses' em que o homem assume o comando de seu destino.
} 
Segundo essa premissa, antes do começo dos tempos existiam seis singularidades: Espaço, Mente, Realidade, Poder, Tempo e Alma. As singularidades foram transformadas em joias e passaram a controlar esses aspectos da existência.

Ao longo das histórias Marvel, as joias vão aparecendo. Os filmes Thor: Mundo Sombrio (2013) e Thor: Ragrarok (2017) mostram, no ano de 2988 AC, a primeira batalha de Svartalfheim: Malekith lidera os Elfos Negros em uma tentativa de destruir os Nove Reinos usando o Éter (Pedra da Realidade). O exército de Asgard, liderado pelo pai de Odin, Bor, derrota Malekith e protege a joia. Odin domina os Nove Reinos e esconde a joia na Noruega onde é recuperada pelo Caveira Vermelha e os nazistas - nos filmes do Capitão América: Guerra Civil (2016) e dos Vingadores (2012, 2015, 2018, 2019). O filme Guardiões da Galáxia (2014) mostra a história de outra joia. A exemplo das séries de histórias em quadrinhos, as narrativas cinematográficas vão se encaixando em torno do projeto de Thanos de reunir as joias para dominar o universo.

Vários vilões permeiam esse percurso até o apocalipse, como pode ser visto no Quadro 3, a seguir:

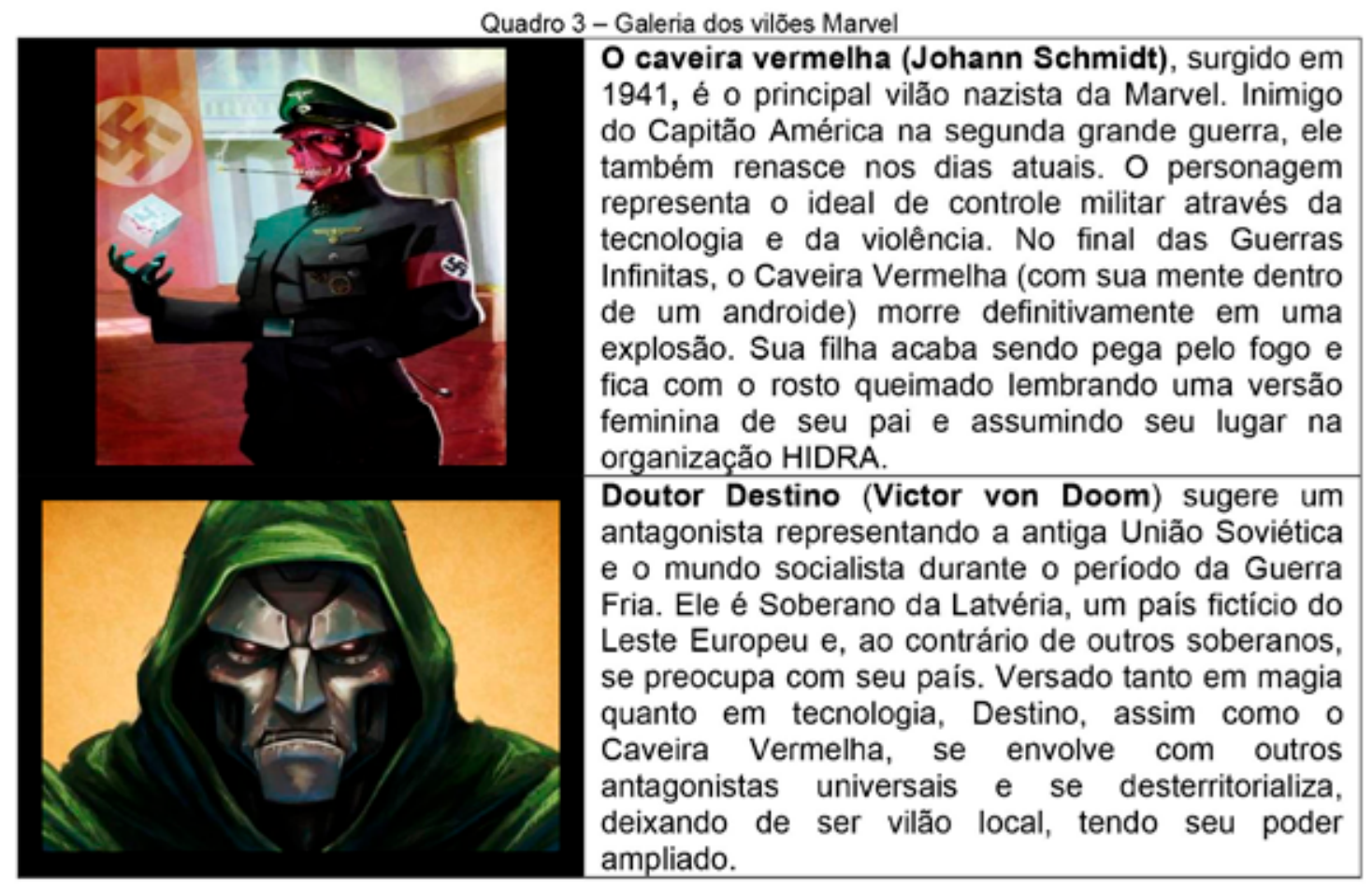




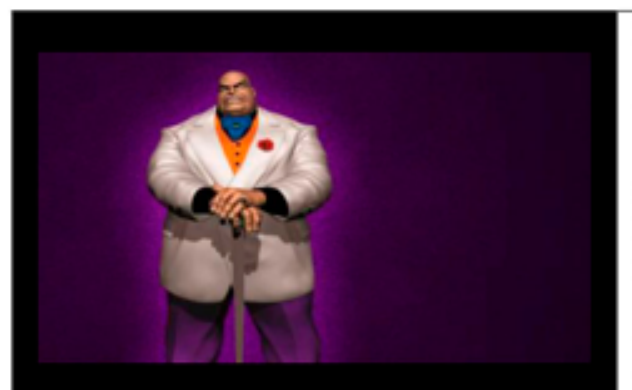

O Rei do Crime (Wilson Fisk), criado em 1967 representa a corrupção sistêmica da burocracia e das autoridades públicas pelo capital? Ele é o predador mais forte e violento, no topo da cadeia alimentar de uma vasta rede de aliados criminosos infiltrados na sociedade. É alguém que deve existir de fato. É um cargo/função mais do que um personagem. Um caso em que o mal intersubjetivo se soma ao mal objetivo, manifesto no contexto territorial do cotidiano.

Magneto (Erik Magnus Lehnsherr), que apareceu em 1963, é o lider de mutantes rebeldes e rival telepático do Doutor Xavier nas sagas dos X-men. A narrativa trata diretamente do tema de exclusão social. Ele considera os mutantes, perseguidos e discriminados pela sociedade, uma raça de evolução superior aos seres humanos, um aperfeiçoamento genético. Em nome dos excluidos, ele deseja exterminar a humanidade e começar uma nova civilização.

Loki, de 1962, é o irmão invejoso do personagem Thor. Sua relação com Thor lembra a do vilão Lex Luthor com Superman (a imperfeiçăo contra o modelo inalcançável), tendo como agravante o fato de que agora se trata do filho legítimo de um pai adotivo. Loki é bem mais astuto e inteligente do que o irmão ingênuo e meio bronco. Ele é o deus da trapaça e da mentira. É um vilão mítico e, na lenda de Thor, é responsável por sua morte pela serpente de Midgard.

Ultron-1 aparece nos quadrinhos em 1968, tendo sido construído pelo Dr. Hank Pym das empresas Stark para ser uma arma. Ele se tornou senciente e se rebelou. Também começou a melhorar o seu design, atualizando-se diversas vezes para se tornar o Ultron-5. O vilão representa o medo da autonomia das máquinas tornar o homem dependente de tecnologia, de tornar a vida mais mecânica e sem afeto, de termos nossa vida programada pelas máquinas e não o contrário.

Galactus estreou em 1966. Personifica a destruição e escraviza o personagem Surfista Prateado como um batedor avançado dos mundos que deseja devorar. Ele age assim porque é sua natureza ser o devorador de mundos. Ele foi o único sobrevivente da última contração do universo que luta para sobreviver até o fim da expansão cósmica iniciada pelo Big-Bang.

Thanos, que aparece nos quadrinhos em 1963, é o vilão máximo do apocalipse do universo Marvel, que consegue reunir as joias do infinito em uma luva, absorvendo todo seu poder e exterminando metade da população de todo universo. 
O design do universo Marvel também pode ser dimensionado a partir de quatro elementos básicos: a) mapas geográficos; b) a linha do tempo atual; c) lista de personagens; e d) sequência histórica e editorial de arcos narrativos. Além de mais probabilístico e flexivel (permitindo o gerenciamento de várias histórias em vários produtos diferentes, simultaneamente), o multiverso Marvel tem uma arquitetura mais complexa, tem uma escala de tempo móvel, é menor do ponto de vista espacial (é mais múltiplo e menos extenso) e mais coletivo (sendo composto por cerca de 17 "grupos" de heróis) do que o universo narrativo da DC.

\section{6 - Arqueologia do "mal" nos quadrinhos de super-heróis}

Interessou-nos, aqui, desenhar a anatomia geral do "mal", na origem e no desfecho da história de cada universo narrativo, estudando seus principais vilões.

\begin{tabular}{|c|c|c|}
\multicolumn{3}{c}{ Quadro 3 - Anatomia do mal representado } \\
\hline DC COMICS & MARVEL COMICS & MAL REPRESENTADO \\
\hline Lex Luthor & \multirow{2}{*}{ Loki } & INVEJA, CIÚME \\
Coringa e Mr. Mxyzptlk & & ESCÁRNIO, VINGANÇA \\
\hline Ra's Al Ghul & Magneto & REVOLTA, ORGULHO \\
\hline Flash Reverso & Hulk vermelho & VAIDADE, SOMBRA \\
\hline Imperiex & Galactus & GULA, DESTRUIÇÃO \\
\hline Darkseid & Thanos & DOMINAÇÃO, MEDO \\
\hline \multicolumn{2}{|c}{ Fonte: o próprio autor. }
\end{tabular}

Com Lex Luthor e Loki são problematizados a inveja e o sentimento de inferioridade. Com o Coringa e Mr. Mxyzptlk discute-se a ridicularização do heroísmo. A diferença está em que os dois primeiros vilões são inferiores aos seus heróis, enquanto os palhaços se consideram superiores aos seus. São representações desproporcionais do mal.

O caso do Flash Reverso é o pavor da igualdade simétrica (um tema mitológico em várias culturas, bastante utilizado na ficção), mas também a representação da sombra, do lado negativo de si, da impossibilidade de vencer a si mesmo. Várias outras narrativas poderiam ser lembradas dessa forma de representação do mal intersubjetivo.

Dos vilões terrestres Doutor Destino, Magneto e Ra's Al Ghul são subversivos e perfeccionistas: desejam destruir a sociedade para reconstrui-lo. Doutor Destino representa o socialismo; Magneto, as minorias excluídas; e Ra's Al Ghul, que é imortal, simboliza o meio ambiente, a terra, o interesse da vida contra o da 
humanidade. O mal aqui é representado como uma vontade legítima de destruir e reconstruir o mundo, como uma violência justificada pela injustiça.

Já Imperiex, Galactus, Darkseid e Thanos querem destruir o universo para reconstruí-lo melhor. Os dois primeiros não são realmente maus, eles apenas se alimentam da energia das estrelas que devoram. $\mathrm{O}$ mal aqui é naturalizado. Temos medo de ser devorados, consumidos. É o mal por engano ou por acaso (o ruído subjetivo). Os protagonistas personificam o mal objetivo, a força entrópica e impessoal do universo, mas descobrem que não passam de mero 'mal intersubjetivo', de que a causa de destruição do universo é a própria existência. Pode-se dizer, repetindo a fórmula dos 'falsos heróis' de Propp (1992, p. 128) que Imperiex e Galactus são 'falsos vilões', uma vez que eles não têm 'maldade', são apenas agentes da destruição.

E Darkseid, Thanos e o Caveira Vermelha (entre outros) representam o desejo de dominação total de todos os mundos e dimensões, de abolir o livrearbitrio como padrão universal e controlar a vida em todos os seus aspectos. São os vilões clássicos, em que o mal objetivo e intersubjetivo se integra de tal modo que não podemos diferenciá-los. Eles são encarnações do mal.

Os vilões são representações de nossos desafetos. É claro que ninguém é inteiramente bom ou mau, mas, nas narrativas dos quadrinhos (seguindo a tradição das narrativas épicas e de contos de fadas), a polarização moral entre os extremos é sempre acentuada de forma pedagógica e indireta, de modo que possamos participar da vitória dos protagonistas e, veladamente, aprender com a derrota dos antagonistas.

As causas de existência de antagonistas em nossas vidas e sonhos são diversas e complexas. Alguns, com inclinação para biologia, acreditam que a consciência moral (ou a distinção entre o bem e o mal) surgiu a partir do desenvolvimento de uma parte da memória filogenética da espécie humana, usada para distinguir as plantas venenosas das nutritivas. Outros, habitantes de um universo mais físico, pensam que o que se chama de mal (oposto à luz) é a força entrópica dos buracos negros. Outros ainda, voltados para o interior, acreditam que a natureza é perfeita e que o mal é um ruido subjetivo que nos impede de viver plenamente essa perfeição. São histórias das origens do mal e das causas ocultas de nosso antagonismo conosco mesmo (GOMES, 2017).

Somos seres miméticos, mimetizamos nossas histórias de outras. Um dia, seremos mimetizados também. Essa é nossa vida. Nossos sonhos são simulações 
de nossas vidas, de nossos medos e esperanças. As estruturas narrativas reduzem a complexidade dos sonhos a histórias que simulam a polaridade entre antagonismo e o protagonismo, entre morte e amor, entre o passado e o futuro.

\section{Conclusão}

Como recurso narrativo das histórias em quadrinhos de superaventuras, magia e tecnologia são soluções semelhantes. Observando essa recorrência, os roteiristas da Marvel estabeleceram um diálogo bem interessante entre os personagens Thor (um semideus decaído) e o Homem de Ferro (o empresário e cientista Tony Stark) sobre as diferenças entre magia e tecnologia.

Depois de muitas idas e vindas, Thor compreende que a tecnologia era uma forma arcaica de metalurgia xamânica e o Homem de Ferro aceita que a magia é uma forma de tecnologia telepática de outras formas de vida. Cada um entende o ponto de vista do outro do seu próprio ponto de vista. Isto só é possível em universo narrativo em que a totalidade do cosmo seja visto de modo complexo, múltiplo e aberto a singularidades.

A importância da descrição e da comparação dos modelos de universo da DC e da Marvel é enorme, não apenas do ponto de vista teórico (uma discussão de física quântica) e narrativo (eles representam formas diferentes de contar histórias: o modelo DC é fechado de multiplicidade interna; o modelo Marvel é aberto e sua pluralidade cresce para fora), mas, sobretudo, editorial - uma vez que toda indústria de entretimento está se transmidiatizando e adotando universos narrativos para organizar suas histórias em várias mídias. Além disso, o universo DC é mais tradicional (imitando os antigos universos tradicionais, voltado para o futuro) e o da Marvel é mais "moderno" (são aventuras imprevisiveis, narrativas de risco, voltadas para o futuro). $\mathrm{O}$ design completo desses modelos de universos narrativos (incluindo os recursos de reboot, redcom, crossover, etc) são paradigmas para o planejamento de marketing das narrativas seriadas transmidias.

Mas não é só isso!

Apenas universos de narrativas seriadas (como as histórias em quadrinhos) nos permitem representar o mundo atual de modo completo e complexo; e elaborar uma 'arqueologia do mal' que represente desde os pequenos delitos do cotidiano até as forças cósmicas de destruição, espelhando uma compreensão moral e 
natural dos conflitos do mundo, sob vários pontos de vista. Ou seja: as histórias em quadrinhos (as narrativas gráficas seriadas) são, através dos universos narrativos, 0 modelo através dos quais outras narrativas estão se organizando e através do qual pensamos nossas adversidades em profundidade. É uma nova mitologia.

\section{Referências bibliográficas}

ANDREOTTI, Bruno; MARANGONI, Adriano.; ZANOLINI, Mauricio. Quadrinhos Através da História: As Eras dos Super-Heróis. São Paulo: Criativo, 2017.

AGOSTINHO, Santo. Confissões. Coleção Os Pensadores. São Paulo: Editora Abril, 1973.

BAUM, L. Frank. O maravilhoso Mágico de Oz. Rio de Janeiro: Vermelho Marinho, 2014.

AVATAR. Direção: James Cameron. Produção: James Cameron, Jon Landau; Roteiro: James Cameron. Elenco: Sam Worthington, Zoë Saldaña, Sigourney Weaver Companhia(s) produtora(s) Lightstorm Entertainment e Dune Entertainment Distribuição: 20th Century Studios. Lançamento: 2009.

CAPITÃO América: Guerra Civil (Captain America: Civil War) Estados Unidos 2016 - cor • 147 min. Direção: Anthony Russo e Joe Russo; Produção: Kevin Feige e Stephen McFeely. Baseado em: Guerra Civil de Mark Millar e Steve McNiven; Elenco: Chris Evans, Robert Downey Jr., Scarlett Johansson; Companhia(s) produtora(s): Marvel Studios. Distribuição Walt Disney Studios Motion Pictures. Lançamento: 2016.

CRISE nas Infinitas Terras. São Paulo: Abril, 1989. 3v.

GOMES, Marcelo Bolshaw. Devaneios da imaginação simbólica. Natal, RN: EDUFRN, 2017. Disponivel em: https://repositorio.ufrn.br/ispui/handle/123456789/24441. Acesso em: 05 jun. 2020.

. O herói das duas faces. Revista $9^{a}$ Arte, São Paulo, Observatório de Histórias em Quadrinhos da Escola de Comunicações e Artes da USP, vol. 5, n. 2, $2^{\circ}$ semestre/2016. Disponivel http://www2.eca.usp.br/nonaarte/ojs/index.php/nonaarte/article/view/198/230. Acesso em: 02 jan. 2020.

Universos sci-fi audiovisuais: estudos narrativos transmindia II. Paraiba: Marca de Fantasia, 2016. Disponivel em https://www.academia.edu/29845416/universos Sci-fi. Acesso em: 05 jun. 2020.

GREIMAS, Algirdas Julien. Semântica estrutural. São Paulo: Cultrix/EdUSP, 1976.

Da imperfeição. Hacker editores: São Paulo, 2002.

GUARDIÕES da Galáxia. Estados Unidos 2014 • cor • 122 min Direção: James Gunn; Produção: Kevin Feige; Roteiro: James Gunn, Nicole Perlman; Baseado em: Guardiões da Galáxia de Dan Abnett e Andy Lanning; Elenco: Chris Pratt, Zoe Saldana, Dave Batista, Vin Diesel, Bradley Cooper; Companhia(s) produtora(s): Marvel Studios. Distribuição: Walt Disney Studios Motion Pictures; Lançamento 2014 
HOMERO. A Iliada. Tradução Frederico Lourenço. Lisboa: Cotovia, 2003.

JENKINS, Henry. Cultura da Convergência. São Paulo: Aleph, 2009.

MOSSMANN, Matheus Machado; BRANCO, Marsal Ávila Alves A manutenção do multiuniverso ficcional dos quadrinhos através de recursos de distorção temporal ou Como Não Matar o Batman? RUA " Revista Universitária do Audiovisual. Dossiê Animação e Arte Sequencial, São Carlos, UFSCAR, dezembro de 2012. Disponivel em: http://www. rua.ufscar.br/a-manutencao-do-multiuniverso-ficcional-dos-quadrinhos-atravesde-recursos-de-distorcao-temporal-ou-como-nao-matar-o-batman/. Acesso em: 10 jan. 2020.

A NOITE mais densa. Barueri: Panini Comics, 2010-2011.

PROPP, Vladimir. Morfologia do conto. Lisboa: Vega, 1992.

RICOUER, Paul. A simbólica do mal. Lisboa: Edições 70, 2013. O mal: um desafio à filosofia e à teologia. Campinas: Papirus, 1988.

THOR: Mundo Sombrio. Thor: The Dark World. Estados Unidos. 2013 • cor • 112 min. Direção: Alan Taylor; Produção: Kevin Feige; Roteiro: Christopher Yost, Christopher Markus, Stephen McFeely. História: Don Payne, Robert Rodat. Baseado em: Thor de Stan Lee, Larry Lieber e Jack Kirby. Elenco: Chris Hemsworth, Natalie Portman, Tom Hiddleston, Anthony Hopkins. Companhia(s) produtora(s): Marvel Studios; Distribuição: Walt Disney Studios Motion Pictures; Lançamento: 2013.

THOR: Ragnarok. Estados Unidos; 2017 • cor • 130 min Direção: Taika Waititi; Produção: Kevin Feige; Roteiro: Eric Pearson; História: Craig Kyle, Christopher Yost, Stephany Folsom. Baseado em Thor por Stan Lee, Larry Lieber e Jack Kirby. Elenco: Chris Hemsworth, Tom Hiddleston, Cate Blanchett, Idris Elba. Companhia(s) produtora(s): Marvel Studios; Distribuição: Walt Disney Studios Motion Pictures. Lançamento: 2017.

TOLKIEN, J. R. R. O senhor dos anéis (A sociedade do anel, As duas torres e O retorno do Rei. São Paulo: editora Martins Fones, 2002.

OS VINGADORES Marvel's The Avengers: Estados Unidos 2012 • cor • 143 min Direção: Joss Whedon; Produção: Kevin Feige; Roteiro: Joss Whedon; História: Zak Penn, Joss Whedon; Baseado em Os Vingadores de Stan Lee e Jack Kirby. Elenco: Robert Downey, Jr.; Chris Evans; Mark Ruffalo; Chris Hemsworth; Scarlett Johansson. Companhia(s) produtora(s): Marvel Studios; Distribuição: Walt Disney Studios Motion Pictures. Lançamento: 2012.

OS VINGADORES: A ERA DE ULTRON. Avengers: Age of Ultron, Estados Unidos 2015 • cor • 141 min Direção: Joss Whedon; Produção: Kevin Feige; Roteiro: Joss Whedon; Baseado em: Os Vingadores de Stan Lee e Jack Kirby. Elenco: Robert Downey Jr.; Chris Hemsworth; Mark Ruffalo; Chris Evans; Scarlett Johansson. Companhia(s) produtora(s): Marvel Studios; Distribuição: Walt Disney Studios Motion Pictures. Lançamento: 2015

OS VINGADORES: GUERRA INFINITA. Avengers: Infinity War. Estados Unidos; 2018 - cor - 149 min Direção: Anthony Russo, Joe Russo. Produção: Kevin Feige; Roteiro: Christopher Markus, Stephen McFeely; Baseado em: Os Vingadores de Stan Lee e Jack Kirby. Elenco: Robert Downey Jr., Chris Hemsworth, Mark Ruffalo, Chris Evans, Scarlett Johansson. 
Companhia(s) produtora(s): Marvel Studios; Distribuição: Walt Disney Studios Motion Pictures; Lançamento: 2018.

OS VINGADORES: ULTIMATO. Avengers: Endgame Estados Unidos $2019 \cdot \operatorname{cor} \cdot 181$ min. Direção: Anthony Russo, Joe Russo; Produção: Kevin Feige; Roteiro: Christopher Markus, Stephen McFeely; Baseado em: Os Vingadores de Stan Lee e Jack Kirby. Elenco: Robert Downey Jr., Chris Evans, Mark Ruffalo, Chris Hemsworth, Scarlett Johansson. Companhia(s) produtora(s); Marvel Studios; Distribuição: Walt Disney Studios Motion Pictures. Lançamento: 2019.

WIENER, Norberto. Cibernética e sociedade. São Paulo: Cultrix, 1954. 